\title{
0 Movimento Como Modo de Criação: a experiência do vivo
}

\author{
Adriana Dal Forno \\ Universidade Federal de Santa Maria - UFSM, Santa Maria/Rio Grande do Sul, Brasil \\ E-mail: adrianadalforno@hotmail.com
}

\section{Resumo}

Este estudo observa aspectos do sistema proposto por Konstantin Stanislávski referentes aos processos de vivência corporificada das ações físicas. Os elementos do sistema atenção, tempo-ritmo, imaginação e plasticidade dos movimentos são apresentados como operadores dos impulsos que efetivam o movimento em ato, e este como produto e produção de vivência, a experiência do vivo. Nesse sentido, os movimentos são portadores de intensidade e de tendências para a tessitura do acontecimento cênico.

Palavras-chave

Ações Físicas. Movimento. Impulso. Konstantin Stanislávski.
Abstract

This study observes aspects of the system proposed by Konstantin Stanislavsky concerning the processes of the embodied living of physical actions. The elements of the system - attention, time-rhythm, imagination and plasticity of movements, are presented as operators of the impulses that effect the movement in act, and this as product and production of experience, the experience of the living. In this sense, the movements are bearers of intensity and tendencies for the texture of the scenic event.

Keywords

Physical Actions. Movement. Impulse. Konstantin Stanislávski. 
-O movimento como modo de criação: a experiência do vivo

Apresento neste artigo, o movimento do corpo como modo de criação de atores e atrizes. A criação implica duas direções: a da vivência ou experiência do vivo ${ }^{1}$ nas suas ações e a composição da cena a partir dos sentidos que os movimentos, compostos em processos de improvisação, apontam por suas tendências para serem elaborados como acontecimento na cena ${ }^{2}$. Considero aspectos do sistema de Konstantin Stanislávski para fundamentar a prática do movimento, especialmente na abordagem do trabalho do ator sobre si mesmo, que visa à descoberta dos caminhos dos impulsos criativos nos processos de vivência e corporificação das ações físicas.

O sistema Stanislávski estruturou-se como uma inovação no trabalho sobre as ações do papel. Nele, a personagem, a cena e os seus elementos difundiam-se do impulso vivo das ações físicas dos artistas, caracterizando-se como uma intersecção entre os processos de vivência e de corporificação e as proposições do papel. A potência do sistema, pela qual é aqui observado, reside em ser um caminho para a constituição da ação viva, independentemente de a cena ser ou não conduzida por personagens, determinada ou não pela elaboração de um papel, assentada ou não em circunstâncias ficcionais e definida ou não pelo realismo a que, muitas vezes, o sistema foi circunscrito.

\footnotetext{
1 Marina Tenório e Diego Moschkovich (in KNEBEL, 2016, p. 26) traduzem perejivánie do russo como "experiência", "vivência", e também como "experiência do vivo". Nas traduções da obra de Stanislávski para o espanhol pela editora argentina Quetzal, pela qual me guio neste trabalho, a noção é traduzida por "vivência".
}

2 Este trabalho é parte da pesquisa de doutorado que realizo no Programa de Pós-Graduação em Artes Cênicas da Universidade Federal do Rio Grande do Sul, sob orientação da professora Dra. Inês Alcaraz Marocco.
$\mathrm{O}$ autor desse sistema, diretor-pedagogo e ator russo, nasceu em 1863 e viveu até 1938. Da juventude a seu falecimento, trabalhou e reuniu pessoas em torno de sua busca pelo redimensionamento do teatro em direção à inspiração, movimento vivo desta arte presencial e relacional no qual o artista "[...] esculpe suas criações com os vibrantes nervos de seu corpo vivo" (STANISLÁVSKI, 1986, p.129, tradução nossa). O que impulsionou Stanislávski, e ainda hoje torna potente seu sistema, foi o estabelecimento de novas condições de criação para um teatro em crise com seu próprio convencionalismo - crise esta causada pela repetição de clichês e pela insuficiência de modos de acercar a inspiração que, segundo ele, é obra da natureza criativa.

Os condicionamentos e convencionalismos renovaram-se desde que o sistema foi elaborado, além de terem proliferado e proliferarem novos pensamentos e poéticas direcionadas à cena. Contudo, a presença de atores e atrizes e a construção da cena continuam sendo questões colocadas a cada nova ação que se quer viva, para a qual o sistema, como uma "atividade-energia", pode ainda ser impulso criativo ${ }^{3}$. Esta presença do vivo na atuação ocorre no sistema pela experiência das ações físicas e pode ser matéria de composição da cena desde as forças que atuam na ação, sem a diretriz da estrutura dramatúrgica de matéria textual.

\footnotetext{
3 O poeta, tradutor e linguista francês Henri Meschonnic (19322009) propõe a noção de historicidade do pensamento, a qual entende como "[...] não somente o momento histórico, sentido puramente historiador e débil de situação de um pensamento. Porém há um sentido forte, direi poético, da noção de historicidade, segundo a qual além dessa situação passada, passiva, resultante pura dos saberes de um lugar e de um momento, há uma atividade-energia [...] que continua atuando mesmo através dos séculos, inclusive através das línguas, enquanto que de acordo com o sentido historiador, o pensamento não é mais que um ergon, um produto" (MESCHONNIC, 2007, p. 29, grifos do autor, tradução nossa). Desse modo, Meschonnic afirma que continuar um pensamento, desde a energia que impulsiona ações, não é repeti-lo.
} 
Pelo exercício de seus elementos constitutivos, o sistema é o modo de acercar a natureza criativa. Ele não é um manual, é um guia, por isso não deve ser aplicado como fórmula de atuação, mas como exercício, trabalho do artista para conectar-se a corrente que guarda "[...] as reservas inesgotáveis da experiência" (STANISLÁVSKI, 1997, p. 305, tradução nossa). Se a experiência que se dá em cada ato é a matéria de criação, os impulsos criativos ocorrem pelas mudanças e variações próprias das relações que se estabelecem na experiência. $O$ sistema opera por elementos que são modos de passagem, gatilhos desses impulsos em seu vir a ser.

A psicotécnica - porque Stanislávski também considera as forças motrizes da vida psíquica e sua dinâmica no trabalho - busca "[...] levar o ator a um estado em que o processo criador subconsciente surge da natureza orgânica mesma" (STANISLÁVSKI, 1980, p. 340, tradução nossa). Quaisquer dos elementos do sistema, seja dos processos de vivência, seja dos processos de corporificação ${ }^{4}$, podem ser instigadores de impulsos, pois têm em comum uma atitude de trabalho que atua desde o consciente para o subconsciente na mais simples ação física, no mais elementar exercício. Stanislávski situava tais impulsos de inspiração como atos inesperados. Quando a mais elementar ação física do artista era carregada pelo inesperado, então mais viva era sua atuação:

Sua atuação é magnífica por seu audaz desprezo pelas normas correntes de beleza. Tem força, mas não pela lógica e coerência que admirávamos no primeiro caso [o ator técnico]. É magnífica por sua audaz falta de lógica. É rítmi-

\footnotetext{
4 Anatoli Vassíliev (in KNEBEL, 2016, p. 127) aborda a noção de voploschénie, que literalmente tem sentido de "encarnação", também como "corporificação" ou "dar corpo" aos processos de vivência.
}

ca por sua falta de ritmo, é psicológica por sua negação da psicologia universalmente aceita. Tem potência por seus impulsos. Infringe as regras correntes, e aí precisamente está sua bondade, sua força (STANISLÁVSKI, 1997, p. 309, tradução nossa).

$\mathrm{O}$ ator e a atriz, o diretor e a diretora e o pedagogo e a pedagoga, nesse sentido, estão envolvidos no mesmo processo do qual a construção da cena derivará. Se, em Stanislávski, essa abertura do campo criativo dos artistas se dirige à fusão das ações físicas com a matéria textual, sua estrutura dramatúrgica e seus papéis, na direção que proponho as ações, são guias da composição da cena, de modo independente das ações textuais, apontando diretivas que não poderiam ter sido pensadas sem as relações que elas próprias estabelecem.

As ações físicas são irrepetíveis enquanto impulso, mesmo sob a construção da partitura do papel, porque incitam e acoIhem o movimento singular que se produz na relação do consciente com o subconsciente, matéria dos impulsos que fazem confluir pensamentos, sensações, sentimentos em sua efetivação. As ações físicas não indicam, imitam ou sintetizam as ações na vida, são, para os que atuam pela arte da vivência, dobras da experiência, das relações que se colocam pelas forças em jogo. A arte do ator e da atriz, desse modo, é produto, produção e composição de impulsos.

Segundo Stanislávski (1997), não se estabeleceriam tais impulsos por "palavras eruditas", menos ainda por inspiração que vem "do alto". As simples ações físicas são a abertura para adentrar no campo do ainda desconhecido. O subconsciente, fonte da inspiração do artista, propõe sentidos inadvertidos às ações, até nas mais casuais, pois tem suas próprias conexões para as quais a consciência é apenas parte do caminho. 
Aqueles para quem tudo está tão claro e simples dizem: a consciência é um farol que ilumina o pensamento para a qual está dirigida a atenção, o resto está na obscuridade. No instante da inspiração o farol ilumina todo o córtex cerebral e então vemos tudo. Magnífico: então ilumine com mais frequência se isto é tão simples (STANISLÁVSKI, 1997, p. 309, tradução nossa).

O movimento constitui a natureza da criação, e é sobre ele que o sistema de Stanislávski opera para colocar atores e atrizes no vórtice de seu fluxo. Os elementos que o constituem são gatilhos que acolhem a vivência e atuam nela. Quando se fala da criação do artista, fala-se de movimento, de mudanças em um fluxo que impulsiona a efetivação das ações físicas. Nesse sentido, o sistema é base do trabalho com o movimento, pois implica os impulsos que o efetivam e coloca-o como um campo de experimentação para a tessitura da cena.

O pedagogo russo buscava tornar acessível a criação aos artistas pela consciência de seus meios, por isso, o trabalho que realiza para este saber não poderia ser generalista, uma vez que cada um tem seu próprio caminho. $O$ trabalho sobre si implicaria "[...] manter uma consciência não ligada ao que se diz, mas a presença no que se faz, sujeito às forças da vida, aos instintos, às sensações, e porque se faz assim e não de outro modo. Isto é o que faz um ator criativo" (STANISLÁVSKI, 1994, p. 89, grifo do autor, tradução nossa).

Para orientar a atividade criativa, Stanislávski (1997) propôs três apoios. O primeiro é a ação, por meio da qual o ator e a atriz se tornam ativos a partir dos impulsos de sua natureza criadora. O segundo apoio é a produção de circunstâncias, que indica a não representação de sentimentos, mas o trabalho de que o sentimento é uma consequência. A ação, desse modo, não repre- senta imagens e paixões de personagens, mas imagens e ações que se produzem pela convergência das ações do papel com a vivência das ações físicas ${ }^{5}$.

Finalmente, como terceiro apoio, através da psicotécnica consciente, o ator e a atriz acessam o subconsciente, compondo ações pelos processos da natureza criadora. A psicotécnica consciente, pelo exercício dos elementos do sistema, atua como gatilho para os processos subconscientes. A inspiração e o subconsciente andam sempre juntos, porém, questionava Stanislávski (1980), como instaurar esse processo conscientemente se o subconsciente não obedece a ordens? O que propõe o autor é que cada ato deve ser desenvolvido até seu limite, ou seja, cada sensação, cada pequeno recurso deve ser detalhado, explorando-se as nuances que envolvem a experiência da ação para estimular novos impulsos. Os detalhes dos "mais insignificantes atos físicos" (STANISLÁVSKI, 1980, p. 343, tradução nossa) devem ser explorados para "organizar" a criação subconsciente. Esses processos produzem novos impulsos em ações que não são representativas de algo, mas força viva. O aprofundamento nos detalhes engaja os artistas nos atos que realizam e produz novas relações. Assim, procede a

\footnotetext{
5 Este aspecto do sistema é trabalhado por meio do mágico "se" e das circunstâncias propostas. Ambas operações formuladas pela imaginação desencadeiam os processos de vivência. As circunstâncias mobilizam e envolvem os atores e as atrizes em objetivos próprios à ação para que não sejam genéricas ou mecânicas. Assim, a ação física nunca é gratuita, pois visa a algo, impulsionando o desejo de sua realização. Os "se" são provocadores de ações pela proposição de circunstâncias e, por isso, são denominados mágicos, porque as incitam instantaneamente. Esses elementos colocam aos artistas um problema para ser respondido com ações físicas pelo envolvimento com que o "se mágico" e as circunstâncias propõem. As referências para a formulação dos "se mágico" e das "circunstâncias propostas" podem ser buscadas na estrutura de ação da matéria textual, podem ainda serem elaboradas pelos artistas por meio da imaginação no processo de estudo com as ações físicas, ou ainda, pela composição entre ambos. Maria Knebel (2016) identifica o "se" como operação que remete a criação dos artistas às intenções do autor da matéria textual.
} 
vivência: como trabalho que explora intensidades que envolvem as ações - imagens, sensações, ritmos, sentimentos.

Os três aspectos do trabalho do ator sobre si mesmo no sistema são desenvolvidos pelo trabalho sobre a vivência e sobre a corporificação. Se a vivência constitui o fluxo vivo nas ações, a corporificação envolve a efetivação desses fluxos, caracterizando cada ação como composição do corpo e do pensamento, da vontade e do sentimento, as forças motrizes que impulsionam o trabaIho de atuação.

O pensamento sugere e dirige a criação pela imaginação, pelo contato com o objeto de relação. As imagens que o compõem são catalisadoras de sentimentos que, por sua vez, aproximam a vontade e os desejos que se apresentam na corrente de sentimentos. A vontade e os desejos, longe de serem uma elaboração eminentemente racional, mostram-se por meio de inclinações, tendências guiadas pelas imagens mentais e por seus sentimentos nos processos de vivência.

Os impulsos podem ser produzidos pelo exercício do elemento comunhão, que inclui contato, relação e adaptação, partes inseparáveis do processo de atuação viva. A comunhão ocorre mediante o estabelecimento de relações por meio do contato com algum objeto de atenção, que pode ser um estar consigo, com o outro ou com um objeto real ou imaginado. Pela intensificação da relação, ocorrem novas adaptações. Esse contato implica a percepção e a entrega ao que se transmite e se recebe, passando pela materialidade dos gestos, das palavras, dos sons, dos movimentos ou das ações usuais e incluindo as forças invisíveis dos sentimentos, dos pensamentos e dos desejos.

$A$ adaptação indica, no processo de comunhão, o modo de efetivação dos fluxos que não podem ser expressos por palavras, operacionalizando o inesperado das relações na composição das ações físicas. Stanislávski (1980) distingue adaptações relativamente conscientes que caracterizam a adequação às circunstâncias propostas, como, por exemplo, a adequação do comportamento a um ambiente em que a hierarquia é um valor, mas sublinha que, na inspiração, as adaptações ocorrem no subconsciente como um ajuste audaz ao inesperado. Como exemplo desse tipo de adaptação, o autor refere-se às crianças, à transparência e à inventividade com que estas expressam as vivências que experimentam. As adaptações podem ser motivadas por gatilhos, dos quais a imaginação é um exemplo. Porém, independentemente de ser ou não uma eleição consciente, sua realização tem mais intensidade quando não projetada, interseccionando a vivência - fluxo de sensações, sentimentos e pensamentos -e a corporificação singular desta.

Stanislávski elege, a partir de determinado ponto de suas pesquisas, o contato, a relação e a adaptação como modos de criação. No adendo ao capítulo sobre a comunhão, escrito por Stanislávski em 1937, na última fase de suas buscas, o autor observa que a comunhão exige o comprometimento de todos os meios do artista. Ele ressalva, então: "Não demonstra isso que o artista pode iniciar sua criação diretamente da comunhão, sem preparar previamente em seu interior o material espiritual necessário para este processo orgânico?" (STANISLÁVSKI, 1980 , p. 375 , tradução nossa). O material espiritual, força motriz da vida psíquica, sucede do contato, da relação, da irradiação e da adaptação. Em nota, os organizadores da obra de Stanislávski informam que este utilizava tal processo, iniciando daí o estudo das ações do papel, não estabelecendo o tema de ensaio em todos os detalhes e criando a partir de improvisações pela interação entre os participantes (STANISLÁVSKI, 1980). 
Ao definir a comunhão em processos de improvisação como modo de trabalho o diretor-pedagogo amplifica o processo de criação dos artistas, abrindo a possibilidade de construção da cena pela composição das ações do antes não percebido, do inadvertido da experiência. A partir dessa perspectiva é que a prática do movimento que proponho também se instaura, ou seja, pelo contato com o corpo em movimento, nos impulsos que esta experiência produz.

\section{-A prática do movimento pelo sistema}

O conjunto das proposições de Stanislávski aqui observadas, conectadas pela noção de ações físicas, efetuam-se na prática do movimento para acessar o fluxo criativo. Pelos mesmos impulsos que propõem às ações físicas, o perceber e o sentir o corpo no trabalho com o movimento podem configurar a vivência, acolhendo os impulsos da experiência que ocorrem no momento de sua efetivação. O movimento, no modo como proponho, além disso, não acontece como resultante de circunstâncias propostas, sejam dadas pela estrutura da matéria textual, sejam criadas pela imaginação dos artistas antes da realização dos movimentos. As circunstâncias são mais um elemento implicado nas forças que convergem em função do momento na realização do movimento. A implicação desta pequena diferença em relação ao sistema propõe ao movimento um encadeamento singular impulsionado pelas qualidades que se apresentam pela vivência e seus impulsos. Desse modo, o movimento será conduzido e composto em ato por relações que passam principalmente pelas sensações dos artistas.

O gesto, na concepção de Hubert Godard (2002, p. 17), pesquisador que atua nas áreas de dança e práticas somáticas, implica "[...] o movimento em todas as suas dimensões afetivas e projetivas", o que lhe confere expressividade. Marie Bardet (2012, p. 168-169, tradução nossa) diz que o gesto, para Godard, é "[...] um movimento que tem alcance significativo" lastreado por uma relação que define uma "atitude na postura" em "[...] uma articulação múltipla entre sensível e imaginário, sensações e apresentação de uma imagem que circula através das corporeidades", ocorrendo por uma atitude atenta ao contexto sempre em mudança. Godard diferencia o gesto do movimento. Este último é entendido por ele como "[...] fenômeno que descreve os deslocamentos estritos dos diferentes seguimentos do corpo no espaço, do mesmo modo que uma máquina produz movimentos" (GODARD, 2002, p. 17). Para ele, o gesto tem uma qualidade específica definida pelo pré-movimento. Este termo refere-se à organização gravitacional da postura que atua sobre a correlação intrínseca entre as emoções e os músculos gravitacionais:
[...] O sistema de músculos gravitacio- nais cuja ação escapa em grande parte à consciência e à vontade, é encarre- gado de assegurar nossa postura. São estes músculos que mantêm nosso equilíbrio e que nos permitem ficar em pé sem que tenhamos de pensar. São ainda estes músculos que registram as mudanças em nossos estados afetivo e emocional. Assim, toda modificação de nossa postura terá uma incidência em nosso estado emocional e, reciproca- mente, toda mudança afetiva provocará uma modificação, mesmo que imper- ceptível, em nossa postura (GODARD, 2002, p.14).

As ações físicas, como o gesto para Godard, carregam qualidades em cada modificação. Essas qualidades procedem da imaginação, das sensações, e sentimentos que the dão impulso e podem caracterizar seu caráter de vivência corporificada. Os 
movimentos que compõem as ações físicas não se referem somente aos deslocamentos do corpo no espaço porque sucedem dos impulsos da vivência e, nesse sentido, correspondem a essa concepção de gesto.

Em suas obras, o mestre russo exemplifica o trabalho com as ações físicas com ações usuais, cotidianas, como abrir uma porta e sentar, por exemplo. Observa, no entanto, os movimentos ou gestos como objetos dessas ações. Stanislávski dispõe, assim, parte do sistema ao trabalho de disponibilização do corpo às ações físicas, pois o diferencial, em sua proposição, é que, por gestos e movimentos em ações usuais, as ações físicas provocam "[...] harmonia de movimentos entre pensamentos e corpo" (STANISLÁVSKI, 1994, p. 215, tradução nossa).

$\mathrm{Na}$ criação que parte do movimento, o acompanhamento das produções do corpo, em sua variabilidade e fluxo, pode coligá-lo à vivência e compor pelas mudanças qualitativas que ocorrem, produzindo adaptações, desenho intenso no espaço ${ }^{6}$. O movimento que constitui cada gesto, cada ação, pode se diferenciar da referência das configurações usuais das ações cotidianas e, ainda assim, efetuar vivência. Nesse sentido, pode haver afinidade com o movimento na dança, considerando-se a perspectiva de que a dança "[...] não é um mero reflexo da realidade que lhe é exterior, mas é sobretudo um processo de construção de formas e de sentidos através da ação do corpo" (FAZENDA in LOUPPE, 2012, p. 07).

O trabalho com o movimento que realizo é desencadeado pelo sentir e perceber as forças que atravessam o corpo e, na con-

\footnotetext{
6 Associo aqui o elemento do sistema adaptação ao que Marie Bardet (2012, p. 133, tradução nossa) observa como uma "sensibilidade ao presente", a propósito da composição na dança improvisada. Esta composição ocorreria como uma relação entre a realidade, que se dá como continuidade e diferenciação, e a presença de uma atenção a essa realidade em curso.
}

dição de disponibilidade a elas, acolher o inesperado. Na etapa inicial de trabalho, não há outra referência que não as conexões dos processos de vivência corporificados. As circunstâncias decorrem da comunhão consigo e com o entorno. A imaginação, nesse sentido, é consequência do atravessamento do movimento no corpo, das relações que este propõe e que, por sua vez, fazem advir imagens mentais que mobilizam sentimentos, sensações, ritmos, novas adaptações ou, ao contrário, a partir do que o movimento propõe como qualidade, tais forças são mobilizadas.

Os impulsos se dão na implicação do corpo no movimento. Esse é o gatilho principal do processo de "presença no que se faz", seja por um modo de perceber a respiração que foge do habitual, seja por desviar da projeção do movimento no espaço e seguir as tendências que o fluxo das vivências sugere, seja por um apoio inusual, o que exige uma reorganização para se manter 0 equilíbrio, por exemplo. A prática do movimento segue as forças que compõem a experiência, especialmente pelos elementos do sistema atenção, imaginação, tempo-ritmo e plasticidade dos movimentos.

$\mathrm{A}$ atenção, um dos elementos desencadeadores de criação no sistema, incita, também pelo movimento, o contato, mobilizando os artistas, em cada relação, para a descoberta de aspectos que impulsionam as ações físicas. A concentração da atenção sobre o corpo, o ambiente, os partners, a imaginação fazem das relações um eixo dos movimentos. Pela atenção, é possível apreender variações e qualidades da experiência e tomá-las como incitação, engajando o artista ao fluxo dos impulsos.

O ritmo, em sua dinâmica, realiza as propensões do movimento variando nas modificações dos impulsos. Seu treino parte da alternância de velocidades no movimento 
para dar a ver, pelas diversas combinações, a influência direta sobre a vivência. $O$ ritmo instiga a percepção e o sentir das sensações, que evocam imagens mentais e sentimentos, colocando-se como operadores de impulsos.

O sentido de visões, por Stanislávski atribuído às imagens, inclui todas as representações imaginárias e sensoriais. As imagens são percebidas pela "visão interior", "[...] a julgar pelas próprias sensações, imaginar, fantasiar, significa em primeiro lugar olhar, ver com a visão interior aquilo no qual se pensa." (STANISLÁVSKI, 1980, p. 109, tradução nossa). Aos artistas, Stanislávski solicita não a imitação dessas imagens, mas a vivência delas pelos artistas, mantendo sobre elas a atenção, pois são mais acessíveis que o sentimento. Não valem por serem mais ou menos reais, mais ou menos críveis, mas pela sensação que despertam.

No trabalho com o movimento, os estados gerados pelas visões permitem que a imaginação torne a afetar o corpo, implicando na circularidade de visualizar, sentir e corporificar em um fluxo de conduta sensorial. A atenção ao corpo, aspecto mais tangível deste trabalho, conecta os movimentos a um ritmo, que funde sensações, sentimentos e pensamento, e estas intensidades se conectam ao vivo da experiência.

O elemento plasticidade do movimento é exercitado no sistema pelo curso do mercúrio imaginário no corpo. Stanislávski propunha a seus alunos o exercício de imaginar uma gota de mercúrio, em suas qualidades específicas de fluxo, e realizar seu percurso pela atenção dirigida ao trânsito desta gota pelo corpo, de forma mais detalhada possível. $\mathrm{O}$ artista é levando a perceber e sentir a energia do mercúrio e das sensações decorrentes de sua mobilidade, caracterizando-a como energia motriz que anima a corrente de movimentos, pela qual se coligam outras forças. A Stanislávski interessava os movimentos plásticos para "[...] tornar visível a vida invisível e criadora do artista" (1997, p. 31, tradução nossa).

O trabalho com o movimento tem esse elemento como uma imagem-potência ${ }^{7}$ sobre a qual a vivência pode tomar corpo, como propunha Stanislávski. Essa imagem potencializa e amalgama a atenção, obtendo direções para o movimento no transcurso das relações por ele mesmo produzidas. 0 fluxo do mercúrio, pelas imagens que evoca, vai dando passagem ao fluxo dos impulsos no movimento. $O$ artista, sentindo e percebendo a energia que se move, faz repercutir sentidos nas disposições de pensamentos e sensibilidades que transcorrem em dinâmicas inesperadas, antes de direções antecipadas $^{8}$.

\footnotetext{
7 Utilizo este termo em referência ao ensaio de Éden Peretta sobre o bailarino de dança butô Kazuo Ohno, que observa as imagens-potência estruturantes da sua dança. Refere-se o autor também à potência das imagens nas palavras com que Ohno conduzia suas oficinas, que, antes de apontar formas para o movimento, impulsionavam a busca poética nos participantes. Como exemplo destas imagens-potências na cena de Ohno: a figura materna, fonte da energia feminina (PERETTA in OHNO, 2016), e na condução do trabalho em suas oficinas, as palavras que seguem: "Acho difícil dançar com a mente vazia. Enquanto se caminha, tome a figura de um inseto. É preciso treinar para se aproximar disso. Não é só se mover o tempo todo. Nem ficar buscando o tempo todo. É estudar junto, caminhar junto e ir, cada vez mais, criando algo de seu. Então vamos, caminhando de lá para cá. Podem andar do jeito que quiserem. Podem andar de lado. Só parar e andar, assim não dá, falta um pouco" (OHNO, 2016, p. 116). O que falta ao "andar e parar" é o caminhar junto com a imagem do inseto. O acompanhamento do mercúrio imaginário, em seu transcurso no corpo, deriva imagens, que como o inseto exemplificado por Ohno, dispõe um caminhar junto de impulso e movimento.
}

8 O filósofo e psicólogo americano William James (1842-1910) precisou o fluxo do real como ultrapassando a lógica, "[...] a realidade, a vida, a experiência, usem a palavra que queiram, excede nossa lógica, a ultrapassa e a circunda". Afirma ele: "[...] assim prefiro chamar a realidade, se não de irracional somente, ao menos não-racional em sua constituição - e por realidade quero dizer a realidade onde as coisas acontecem, toda realidade temporal sem exceção -" (JAMES, 2009, p. 134, tradução nossa). A única maneira de aprender a realidade em sua densidade é experimentá-la diretamente, sendo parte dela, para qual James observa a "[...] escuta passiva e receptiva ao invés do esforço por raciocinar ruidosa e verbalmente sobre tudo, que é nossa 
A gota de mercúrio encaminha o artista à experiência, desencadeando os impulsos que efetivam a vivência no movimento. A linha contínua de energia que se move no corpo e com o corpo - mercúrio imaginário configura ritmo no tempo de seu efetuar-se contínuo, em que é possível "[...] acelerar, retardar, deter, interromper, agregar acento rítmico, e, por fim, coordenar nossos movimentos com a ênfase do tempo e do ritmo" (STANISLÁVSKI, 1997, p. 49, tradução nossa).

É a partir desses elementos, principalmente, que abordo o trabalho de criação pelo movimento, no qual, desde as variações qualitativas da vivência, efetivam-se qualidades ao movimento no espaço. Seu exercício ocorre como movimento em ato, como experiência que está se realizando. Todo movimento se dá em ato, mesmo na existência de uma partitura. O que ocorre é que esse processo se intensifica pela composição em ato, pois se sustenta nos impulsos que decorrem da experiência do movimento. Assim, confere outra dimensão ao exercício de improvisar, que atenta para o inesperado das relações que a composição em ato assume, agudizando o aproveitamento dos limites de cada ação na apreensão das singularidades que se produzem. 0 contato, a adaptação e a relação caracterizam a improvisação, que, pela proposição da comunhão, torna-se efetivação da vivência corporificada ${ }^{9}$.

usual pose intelectual" (JAMES, 2009, p. 160, tradução nossa).

9 Marie Bardet, em referência ao trabalho da dança de Steve Paxton pelo Contact Improvisation, aborda a improvisação pela exploração do limite da relação com o presente e seus graus de efemeridade na produção do gesto. Para a autora, a improvisação proporciona, antes que uma forma de dança, "[...] a experiência do grau de imprevisibilidade de todo ato criador" (BARDET, 2012, p. 123). Discorrendo sobre a exploração paradoxal dos limites da composição, da passividade e da atividade, da sensação e do gesto, da temporalidade percebida no imediato, Bardet (2012, p. 131) configura a improvisação como o contato com os movimentos do ritmo que mudam: "[...] improvisar implica então em centrar sua atenção sobre a composição sempre
No trabalho com o movimento em ato, a atenção tem um guia: o corpo. A atenção ao corpo em relação por um perceber e sentir dá ao artista a disposição das mudanças e variações que caracterizam o fluxo do que é vivo ${ }^{10}$. A composição ocorre desde esses impulsos, articulando seu fluxo à efetivação do movimento, e, desse modo, não é pensada ou desenhada com anterioridade, sendo gerativa de disposições e tendências para o movimento. Dessa forma, produzem-se corpos, sensações, sentimentos e pensamentos não previsíveis.

A composição que decorre dos movimentos em ato deriva da intensidade que os produziu, sugerindo sentidos e modos de elaborações que envolvem desde as tessituras mais fixas ate as mais performativas. Os impulsos, sempre em mudança a cada organização e cada momento de ação, serão os guias para os artistas que atuam em qualquer opção. Na organização da cena, etapas sucedem-se desde a produção dos primeiros materiais; cabe ao artista acolher, ou transformar, ou elaborar o fluxo que este material propõe à conjugação. $O$ impulso que o movimento em ato lançou, e que con-

já em ato na percepção, esculpir e mudar com precisão na multiplicidade do que acontece e é produzido, e tornar presente a ausência esculpindo no vivo da presença em curso".

10 Para Erin Manning, filósofa e artista canadense, este perceber é relativo. De qualquer modo, diz a autora, um campo de intensidade abre-se entre o que é percebido e não percebido, porém sentido. Manning propõe a noção de preensão negativa, advinda da filosofia da experiência do britânico Alfred North Whitehead (1861-1947), que define como "[...] a preensão é uma compreensão-em-direção-a pela qual a experiência se faz sensível" (MANNING, 2016, p. 24). O acontecimento, pela proposição do filósofo, é arrastado para a experiência. Nesse processo, para o acontecimento se tornar consistente, se atualizar, muito das relações vividas na experiência do acontecimento é colocado em segundo plano. "A preensão negativa é negativa apenas no sentido de eliminar um certo conjunto de dados tendo em vista permitir a consistência do primeiro plano na atualização do que vem a ser" (MANNING, 2016, p. 25). O fato de esses dados não serem passíveis de serem percebidos, não quer dizer, no entanto, que não afetem o acontecimento. que não afetem o acontecimento. Este imperceptível sensível, em relação com o perceptível, forma a variação na experiência vivida, seu movimento. 
tinuará lançando nas sucessivas ações sobre o material elaborado, propõe relações singulares à matéria textual, quando os projetos artísticos a incluem, como pode constituir cena sem essa referência. Depois do que o movimento em ato provê, em relações singulares e inesperadas, são as escolhas poéticas que definirão o acontecimento cênico.

\section{Referências}

BARDET, Marie. Pensar con mover: un encuentro entre danza y filosofía. Tradução de Pablo Aires. Buenos Aires: Cactus, 2012.

GODARD, Hubert. Gesto e percepção. Tradução de Silvia Soter. In: PEREIRA, Roberto; SOTER, Silvia (Orgs.). Lições de Dança 3. Rio de Janeiro: UniverCidade Editora, 2002. P. 11-34.

JAMES, Willian. Un universo pluralista: filosofía de la experiencia. Tradução de Sebastián Puente e Leonel Livchits. Buenos Aires: Cactus, 2009.

KNEBEL, Maria. Análise-ação: práticas das idéias teatrais de Stanislávski. Organização, adaptação e notas de Anatoli Vassíliev; tradução e notas adicionais de Maria Tenório e Diego Moschkovich. São Paulo: Editora 34, 2016.

LOUPPE, Laurence. Poética da dança contemporânea. Tradução de Rute Costa. Lisboa: Orfeu Negro, 2012.

MANNING, E. Por uma pragmática da inutilidade, ou o valor do inframince. Galáxia, São Paulo, n. 31, p. 22-40, abr. 2016. Disponível em: http://www.scielo.br/scielo.php?pi$\mathrm{d}=\mathrm{S} 1982-25532016000100022 \&$ script=sci abstract\&tlng=pt. Acesso em: 22 fev. 2018.

MESCHONNIC, Henri. La poesía como crítica del sentido. Tradução de Hugo Savino. Buenos Aires: Marmol - Izquierdo Editores, 2007.

OHNO, Kazuo. Treino e $(m)$ poema. Tradução de Tae Suzuki. São Paulo: n-1 edições, 2016.

STANISLÁVSKI, Constantin. El trabajo del actor sobre sí mismo: el trabajo sobre sí mismo en el proceso creador de las vivencias. Tradução de Salomón Merener. Buenos Aires: Editorial Quetzal, 1980.

. Trabajos teatrales: correspondencia. Tradução de Luis Sepúlveda. Buenos Aires: Editorial Quetzal, 1986.

Etica y disciplina: método de acciones fisicas (propedéutica del actor). seleção e notas de: Edgar Ceballos. Tradução de Margherita Pavia e Ricardo Rodrígues. México: Col. Escenología, Editorial Gaceta, 1994.

. El trabajo del actor sobre sí mismo: el trabajo sobre sí mismo en el proceso creador de la encarnación. Tradução de Salomón Merener. Buenos Aires: Editorial Quetzal, 1997.

Recebido: 24/04/2019 Aprovado: 06/07/2019 